\title{
Cytogenetic and molecular characterization of eight new reciprocal translocations in the pig species. Estimation of their incidence in French populations
}

\author{
Alain Ducos ${ }^{\mathrm{a} *}$, Alain PINTON ${ }^{\mathrm{a}}$, \\ Martine Yerle ${ }^{\mathrm{b}}$, Anne Séguéla ${ }^{\mathrm{a}}$, Hélène-Marie Berland ${ }^{\mathrm{a}}$, \\ Corinne Brun-BARONNAT ${ }^{\mathrm{a}}$, Nathalie BONNET ${ }^{\mathrm{a}}$, Roland DARRÉ ${ }^{\mathrm{a}}$ \\ ${ }^{a}$ UMR INRA-ENVT de cytogénétique des populations animales, \\ École nationale vétérinaire de Toulouse, \\ 23 Chemin des capelles, 31076 Toulouse Cedex 3, France \\ ${ }^{\mathrm{b}}$ Institut national de la recherche agronomique, Laboratoire de génétique cellulaire, \\ Auzeville BP 27, 31326 Castanet-Tolosan Cedex, France
}

(Received 25 October 2001; accepted 20 December 2001)

\begin{abstract}
Eight new cases of reciprocal translocation in the domestic pig are described. All the rearrangements were highlighted using GTG banding techniques. Chromosome painting experiments were also carried out to confirm the proposed hypotheses and to accurately locate the breakpoints. Three translocations, $\operatorname{rcp}(4 ; 6)(\mathrm{q} 21 ; \mathrm{p} 14), \operatorname{rcp}(2 ; 6)(\mathrm{p} 17 ; \mathrm{q} 27)$ and $\mathrm{rcp}(5 ; 17)(\mathrm{p} 12 ; \mathrm{q} 13)$ were found in boars siring small litters ( 8.3 and 7.4 piglets born alive per litter, on average, for translocations $2 / 6$ and $5 / 17$, respectively). The remaining five, $\operatorname{rcp}(5 ; 8)(\mathrm{p} 12 ; \mathrm{q} 21)$, $\operatorname{rcp}(15 ; 17)(\mathrm{q} 24 ; \mathrm{q} 21), \operatorname{rcp}(7 ; 8)(\mathrm{q} 24 ; \mathrm{p} 21), \operatorname{rcp}(5 ; 8)(\mathrm{p} 11 ; \mathrm{p} 23)$ and $\mathrm{rcp}(3 ; 15)(\mathrm{q} 27 ; \mathrm{q} 13)$ were identified in young boars controlled before entering reproduction. A decrease in prolificacy of $22 \%$ was estimated for the $3 / 15$ translocation after reproduction of the boar carrier. A parental origin by inheritance of the translocation was established for the $(5 ; 8)(\mathrm{p} 11 ; \mathrm{p} 23)$ translocation. The overall incidence of reciprocal translocations in the French pig populations over the 2000/2001 period was estimated $(0.34 \%)$.
\end{abstract}

chromosome / reciprocal translocation / pig / reproductive performance / chromosome painting

\footnotetext{
* Correspondence and reprints

E-mail: a.ducos@envt.fr
} 


\section{INTRODUCTION}

Structural chromosomal abnormalities have long been studied in the pig species. The first one was identified and described almost 40 years ago [14]. Control programmes were initiated in several European countries as early as the beginning of the 1970's. Based on karyotypic analyses of hypoprolific boars detected using national herd management databases [19], they led to the discovery of numerous chromosomal rearrangements, mainly reciprocal translocations $[4,8]$. The continuous improvement of chromosome banding techniques [27] made it possible, during the last decade, to identify and characterize new rearrangements modifying very slightly the morphology and/or the banding profile of the chromosomes. One hundred or so structural chromosomal abnormalities have been published so far $[4,10]$. In France, the very important development of artificial insemination (AI) since the end of the 1980's [12] has resulted in an intensification of the control programmes, and in a drastic modification of their structure [10]. Presently, about $90 \%$ of the analyses carried out in our laboratory concern young purebred boars controlled before reproduction (mainly AI) on the selection and multiplication levels (animals with high diffusion potentials). The chromosomal control of hypoprolific boars has been maintained, but the detection methods of such animals have evolved (use of the new information system built for BLUP-animal model indexation purposes [32], decentralization of the detection procedures). Nine new chromosomal rearrangements were detected within these control activities during the January 2000 to June 2001 period, including one pericentric inversion (analysis in progress) and eight reciprocal translocations described in this paper.

\section{MATERIALS AND METHODS}

\subsection{Animals}

Between January 2000 and June 2001, 1730 chromosomal analyses were carried out in our laboratory in the pig species. Most of them (1450) corresponded to young phenotypically normal purebred boars controlled independently before reproduction. The remaining 280 concerned hypoprolific boars, as well as relatives of animals carrying chromosomal rearrangements (family analyses).

The main characteristics of the animals carrying reciprocal translocations are presented in Table I.

\subsection{Cytogenetical analyses}

The mitotic chromosomes of the translocated pigs and their relatives were prepared from non-synchronized cultures of peripheral blood lymphocytes. Whole blood $(0.5 \mathrm{~mL})$ was cultured during $72 \mathrm{~h}$ in a medium consisting of 
Table I. Chronological list of the cases studied. Main characteristics of the carrier animals.

\begin{tabular}{|c|c|c|c|c|c|}
\hline Case $\mathrm{N}^{\circ}$ & Date & Breed & Reason of control & Rearrangement & Familial analyses carried out \\
\hline 1 & January 2000 & Piétrain & $\begin{array}{l}\text { Boar siring small } \\
\text { litters }\end{array}$ & $\operatorname{rcp}(4 ; 6)(q 21 ; p 14)$ & none \\
\hline 2 & January 2000 & Large White & $\begin{array}{l}\text { Candidate for } \\
\text { reproduction }\end{array}$ & $\operatorname{rcp}(5 ; 8)(\mathrm{p} 12 ; \mathrm{q} 21)$ & sire + one sister \\
\hline 3 & March 2000 & $\begin{array}{l}\text { French Landrace } \\
\text { (FL) }\end{array}$ & $\begin{array}{l}\text { Candidate for } \\
\text { reproduction }\end{array}$ & $\operatorname{rcp}(15 ; 17)(\mathrm{q} 24 ; \mathrm{q} 21)$ & $\begin{array}{l}\text { dam }+ \text { one sister }+ \text { one } \\
\text { maternal half-sib (sire } \\
\text { controlled earlier) }\end{array}$ \\
\hline 4 & June 2000 & $\begin{array}{l}\text { Crossbred (3/4 FL; } \\
\text { 1/4 Meishan) }\end{array}$ & $\begin{array}{l}\text { Candidate for } \\
\text { reproduction }\end{array}$ & $\operatorname{rcp}(7 ; 8)(q 24 ; p 21)$ & $\begin{array}{l}\text { dam }+ \text { one full-sib (purebred } \\
\text { FL paternal grand-sire } \\
\text { controlled earlier) }\end{array}$ \\
\hline 5 & October 2000 & Yorkshire & $\begin{array}{l}\text { Boar siring small } \\
\text { litters }\end{array}$ & $\operatorname{rcp}(2 ; 6)(\mathrm{p} 17 ; \mathrm{q} 27)$ & none \\
\hline 6 & October 2000 & Yorkshire & $\begin{array}{l}\text { Boar siring small } \\
\text { litters }\end{array}$ & $\operatorname{rcp}(5 ; 17)(\mathrm{p} 12 ; \mathrm{q} 13)$ & none \\
\hline 7 & November 2000 & $\begin{array}{l}\text { Sino-European } \\
\text { synthetic line }\end{array}$ & $\begin{array}{l}\text { Candidate for } \\
\text { reproduction }\end{array}$ & $\operatorname{rcp}(5 ; 8)(\mathrm{p} 11 ; \mathrm{p} 23)$ & 6 full- and half-sibs \\
\hline 8 & February 2001 & Large White & $\begin{array}{l}\text { Candidate for } \\
\text { reproduction }\end{array}$ & $\operatorname{rcp}(3 ; 15)(q 27 ; q 13)$ & offspring (analyses in progress) \\
\hline
\end{tabular}


$10 \mathrm{~mL}$ TC199 (Gibco), 20\% autologous serum, 500 UI Heparin (Sanofi) and stimulated with $0.2 \mathrm{~mL}$ Pokeweed Mitogen (Gibco). Hypotonic treatment $(10 \mathrm{~mL} 1 / 6$ calf serum) was followed by pre-fixation and fixation in ethanol:acetic acid (3:1). Chromosome preparations were spread on cold wet slides and air dried. Slides were treated with $0.1 \%$ Trypsin (Difco) and stained with 3\% Giemsa solution to generate GTG-banding [30]. Chromosomes were arranged according to the standardized karyotype of the domestic pig [6]. At least 10 metaphases were karyotyped in each case.

Dual-color chromosome painting was carried out, except for case 3 (no chromosomal material was kept), to confirm the hypotheses put forward as a result of the banding techniques. Chromosome-specific painting probes were produced using DOP-PCR amplification [31] of flow sorted L52 swine chromosomes [29,33]. Fluorescence in situ hybridization was performed according to [33]. Biotinylated probes were detected using avidin conjugated to Texas Red and amplified using goat biotinylated anti-avidin antibody. The digoxygenin-labeled probes were detected with sheep anti-digoxygenin antibody conjugated to FITC (all detection products were from Vector Laboratories). The chromosomes were counterstained with DAPI, and the slides were mounted in an antifade solution. Digital images were obtained using a Zeiss Axiophot epifluorescence microscope coupled to a CCD camera. A Cytovision workstation (Applied Imaging) was used for camera control, image acquisition, pseudocolored image merging and image treatment.

\section{RESULTS}

\subsection{Cytogenetical analyses}

Case 1 - A careful analysis of the boar's metaphases allowed us to identify relatively easily a rearranged chromosome 6 exhibiting abnormally long parms (Fig. 1a). A rearranged chromosome 4 lacking its q-terminal region was then pointed out when carrying out the karyotypes. The fragment $(4 \mathrm{q} 21 \rightarrow$ 4qter) was found without ambiguity at the extremity of the short arms of the chromosome der(6). The reciprocity of the translocation could be demonstrated very clearly using the chromosome painting approach (Fig. 1b), but it was difficult to prove using banding techniques only, due to the very small size of the chromosome fragment translocated from chromosome 6 to chromosome der(4). The chromosomal rearrangement could be described, according to the standard nomenclature, as 38,XY,rcp $(4 ; 6)(\mathrm{q} 21 ; \mathrm{p} 14)$.

Case 2 - This rearrangement was much more difficult to identify than the previous one. A long metaphasic abnormal chromosome was initially observed. A thorough examination led us to hypothesize that this chromosome was a rearranged chromosome 5 whose p-arms were almost entirely replaced 
a)

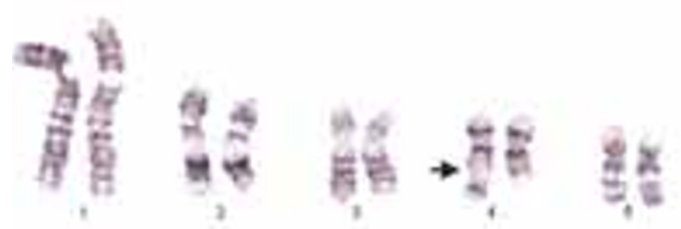

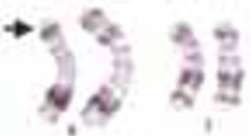

$\frac{25}{9}$ \&

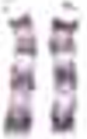

a 8
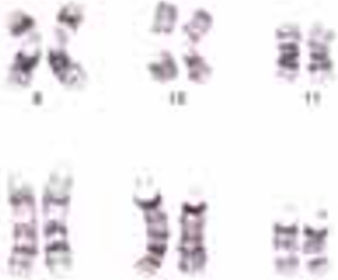

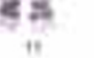

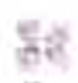

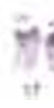

Figure 1. $r c p(4 ; 6)(q 21 ; p 14)$

a) GTG-banding karyotype: the normal chromosomes are on the left, the rearranged chromosomes on the right; the locations of the breakpoints are indicated by arrows.

b) Dual-color chromosome painting: metaphase spread of a pig heterozygous carrier of the rearrangement. b)

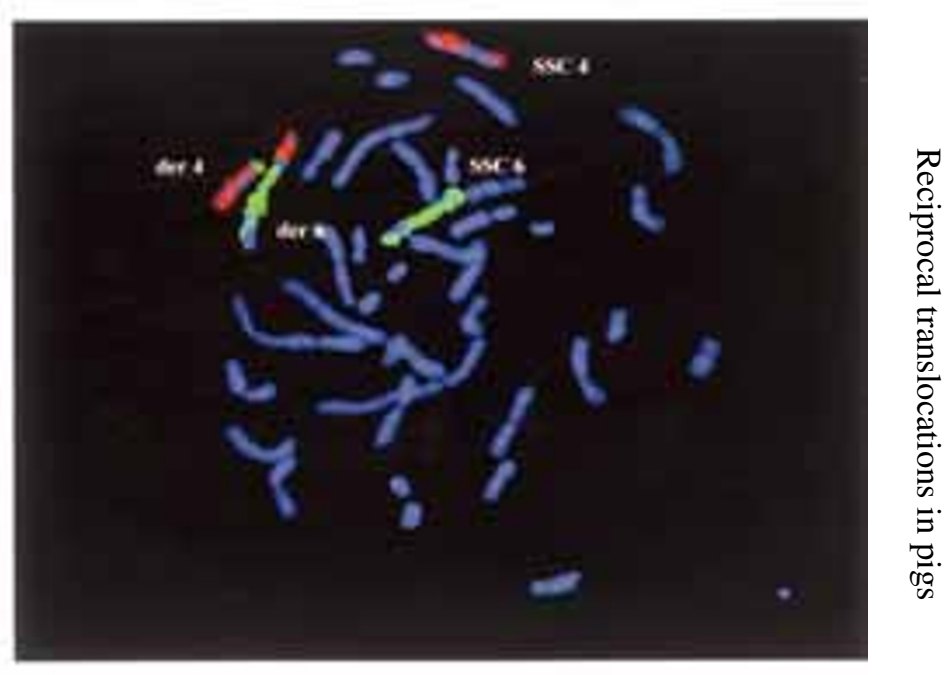


(breakpoint near the centromere, in the $5 \mathrm{p} 12$ band) by the main part of the long arms of one chromosome 8 (8q21 $\rightarrow$ 8qter). Reciprocally, the $(5 \mathrm{p} 12 \rightarrow 5$ pter $)$ fragment, representing about $90 \%$ of the chromosome $5 \mathrm{p}$-arms, was found at the extremity of the der(8) chromosome (Fig. 2a). The chromosome painting analyses carried out in this case (Fig. 2b) clearly confirmed this interpretation. The chromosomal rearrangement could be described as 38,XY,rcp $(5 ; 8)(\mathrm{p} 12 ; \mathrm{q} 21)$.

Case 3 - This rearrangement, like the previous one, altered the chromosome morphologies very slightly. The most visible modification was the abnormal dark band at the extremity of one (rearranged) chromosome 17 (Fig. 3). The identification of the second chromosome pair involved in the rearrangement was more difficult. Nevertheless, the realization of 10 karyotypes allowed us to identify an abnormally long light band (corresponding to the $17 \mathrm{q} 21 \rightarrow$ 17 ter fragment) at the terminal extremity of one rearranged chromosome 15 , and the concomitant lack of the very characteristic $15 q 25$ band $(15 q 24 \rightarrow$ 15 ter fragment translocated to the der(17) chromosome). The chromosomal rearrangement could be described as 38,XY,rcp $(15 ; 17)(\mathrm{q} 24 ; \mathrm{q} 21)$.

Case 4 - The absence of the characteristic fine dark band at the extremity of the q-arms of one chromosome 7 was rapidly detected (Fig. 4a). However, as in the previous case, the identification of the second chromosome pair involved in the rearrangement (pair 8) was much more difficult. The hypothesis of breakpoints located in the $7 \mathrm{q} 24$ and $8 \mathrm{p} 21$ bands, as well as the reciprocity of the chromosomal exchange, could be confirmed using chromosome painting techniques (Fig. 4b). The chromosomal rearrangement could be described as $38, X Y, \operatorname{rcp}(7 ; 8)(\mathrm{q} 24 ; \mathrm{p} 21)$.

Case 5 - The analysis of the animal's metaphases revealed a long almost symmetrical, metacentric abnormal chromosome, looking like an isochromosome $2 \mathrm{q}$ (Fig. 5a). However, a chromosome 6 truncated in its q-terminal region was rapidly identified, the missing fragment $(6 \mathrm{q} 27 \rightarrow$ 6qter) being observed at the extremity of the p-arms of one rearranged chromosome 2 . The reciprocity of the chromosomal exchange could be demonstrated using chromosome painting (Fig. 5b). The chromosomal rearrangement could be described as 38,XY,rcp $(2 ; 6)(\mathrm{p} 17 ; \mathrm{q} 27)$.

Case 6-The very small sized rearranged chromosome 17 was easily detected on the animal's metaphases (Fig. 6a). An abnormal grey band was subsequently identified at the extremity of the p-arms of one rearranged chromosome 5. The difference between the normal and rearranged chromosome 5 was relatively fine. The hypothesis that the breaks occurred near the centromere on both chromosomes, in the 5p12 and 17q12 bands, respectively, was verified by chromosome painting (Fig. 6b). The residual centromeric chromosome 17 fragment on the der(17) chromosome appeared as not stained by the painting probe used (there was no green signal near the centromere). The presence of two small yellow dots at the breakpoint on this rearranged chromosome proved 
a)

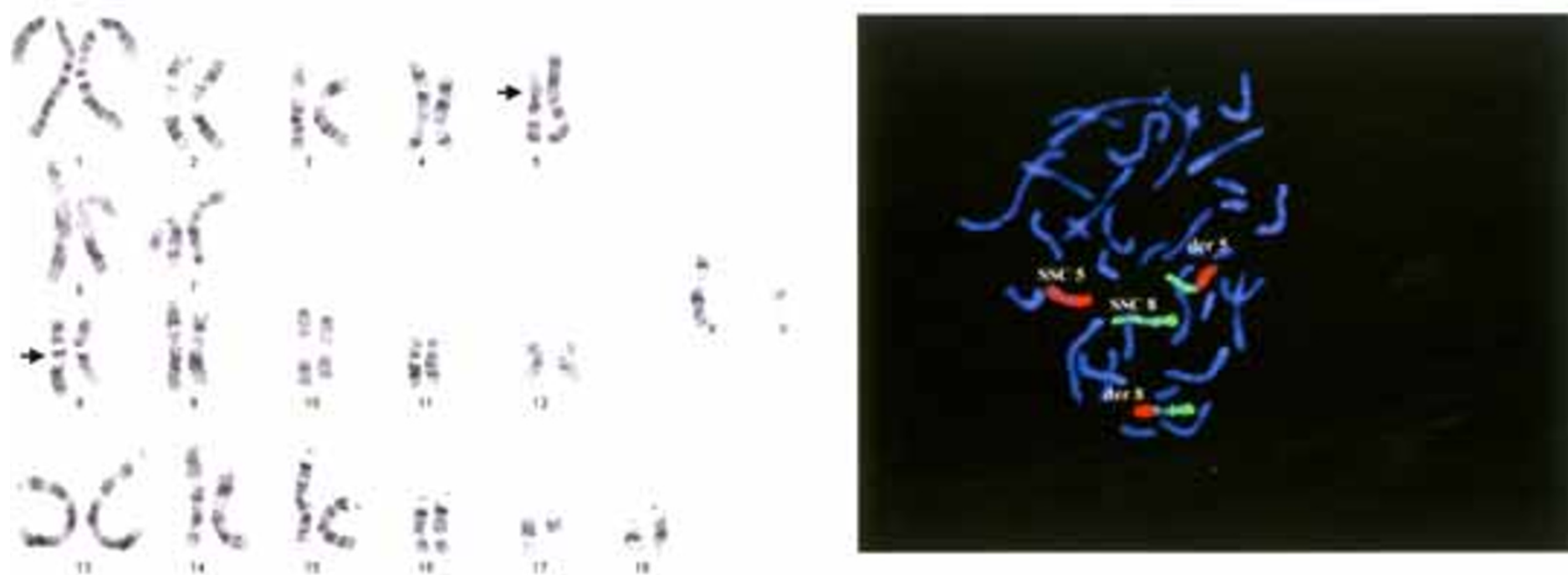

b)

0
0
0
0
0
0
0
0
0
0
0
0
0
0
0
0
0
0
$\vdots$
0
0.
0.
0
0.

Figure 2. $\operatorname{rcp}(5 ; 8)(\mathrm{p} 12 ; \mathrm{q} 21)$

a) GTG-banding karyotype: the normal chromosomes are on the left, the rearranged chromosomes on the right; the locations of the breakpoints are indicated by arrows.

b) Dual-color chromosome painting: metaphase spread of a pig heterozygous carrier of the rearrangement. 


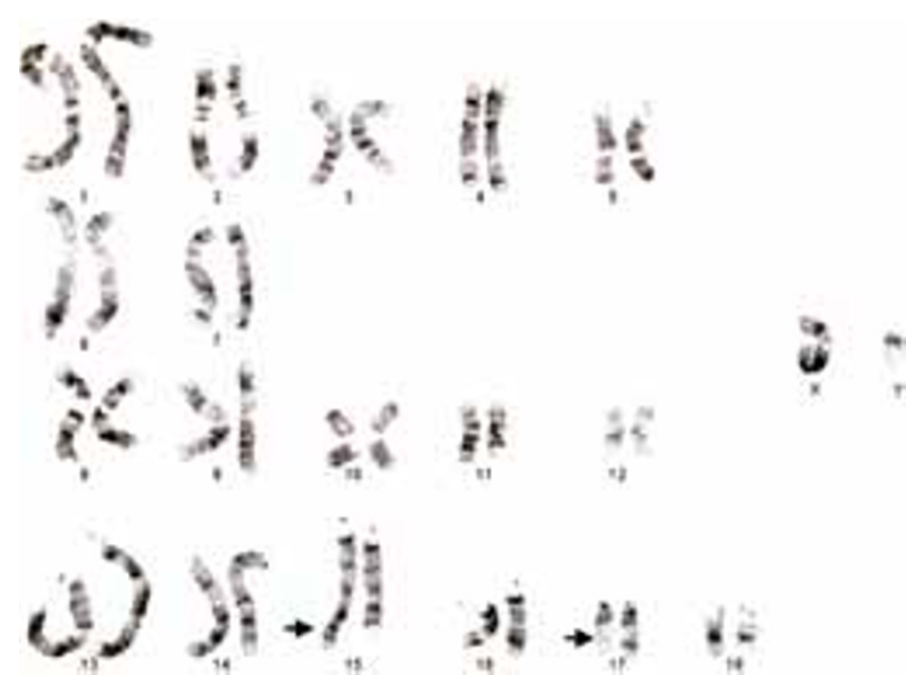

Figure 3. $\operatorname{rcp}(15 ; 17)(\mathrm{q} 24 ; \mathrm{q} 21)$

a) GTG-banding karyotype: the normal chromosomes are on the left, the rearranged chromosomes on the right; the locations of the breakpoints are indicated by arrows.

the presence of chromosome 17 material and helped to demonstrate the origin of the unstained centromeric region of chromosome 17. The chromosomal rearrangement could be described as $38, \mathrm{XY}, \mathrm{rcp}(5 ; 17)(\mathrm{p} 12 ; \mathrm{q} 12)$.

Case 7 - A rapid examination of the animal's metaphases gave us the impression that we were faced with a trisomy 10 (Fig. 7a). However, a more thorough analysis revealed that the chromosome considered as a supernumerary chromosome 10 was in fact a rearranged chromosome 5 lacking its short arms (breakpoint in $5 \mathrm{p} 11)$. The corresponding fragment $(5 \mathrm{p} 11 \rightarrow 5$ pter) appeared as a p-terminal band on chromosome $\operatorname{der}(8)$. The reciprocity of the chromosomal exchange could not be proved using banding techniques only, due to the very small size of the chromosome fragment translocated from chromosome 8 to chromosome 5. Conversely, the chromosome painting experiments (Fig. 7b) revealed the presence of a very thin p-terminal green band on the der(5) chromosome, demonstrating the reciprocity of the exchange, and allowed an accurate localization of the breakpoint on the p-terminal extremity of chromosome 8 ( $8 \mathrm{p} 23$ band). The chromosomal rearrangement could be described as 38,XY,rcp (5;8)(p11;p23).

Case 8 - This abnormality was easily identified due to the presence of two very particular rearranged chromosomes (Fig. 8a). The first one, the smallest of the karyotype, corresponded to the chromosome der(15), whereas the second one, much longer and comparable in size to a chromosome 1, corresponded to the chromosome der(3). The main part of one chromosome 15 
a)

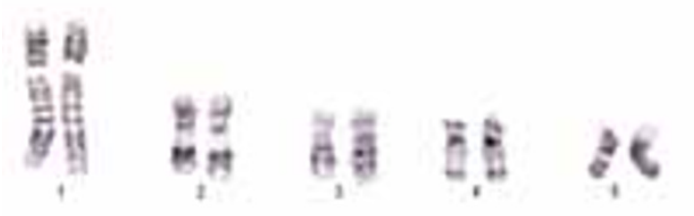

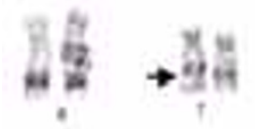

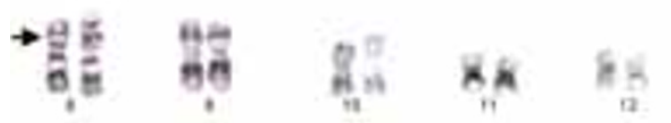

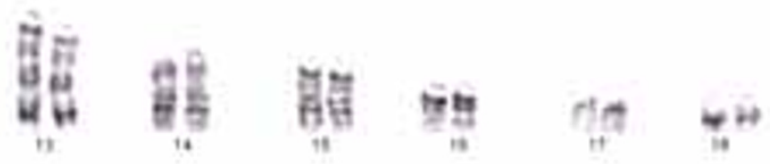

b)

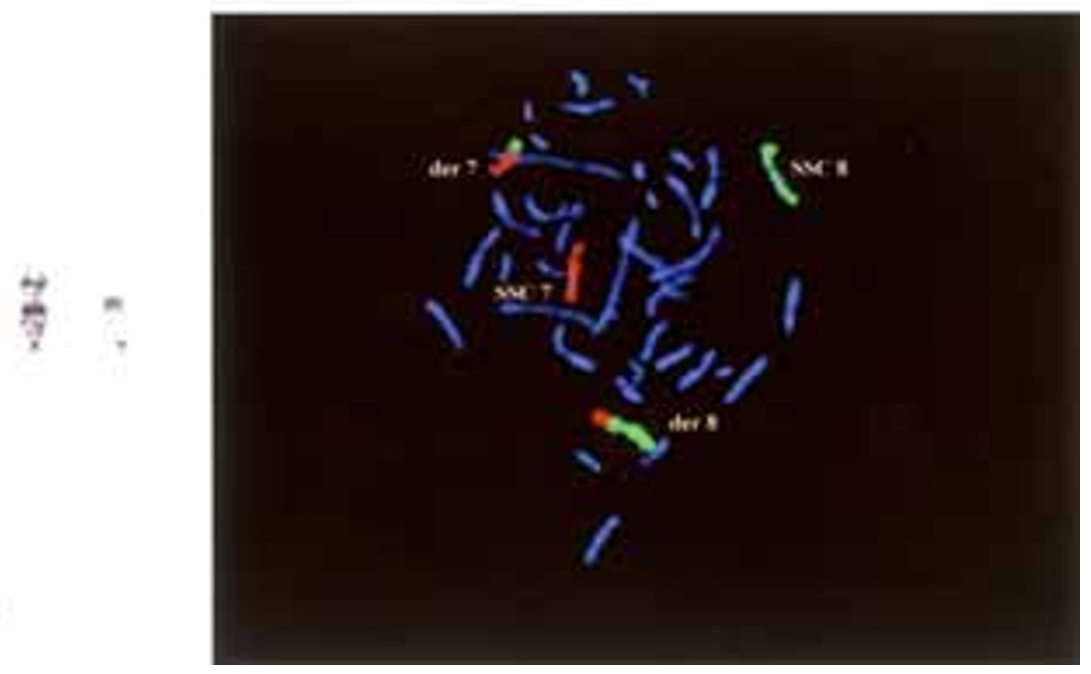

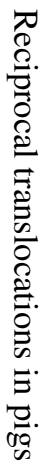

Figure 4. $\operatorname{rcp}(7 ; 8)(\mathrm{q} 24 ; \mathrm{p} 21)$

a) GTG-banding karyotype: the normal chromosomes are on the left, the rearranged chromosomes on the right; the locations of the breakpoints are indicated by arrows.

b) Dual-color chromosome painting: metaphase spread of a pig heterozygous carrier of the rearrangement. 
a)

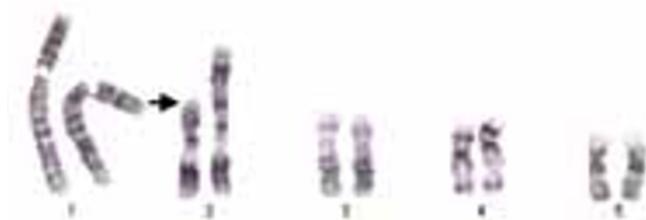

+16 is
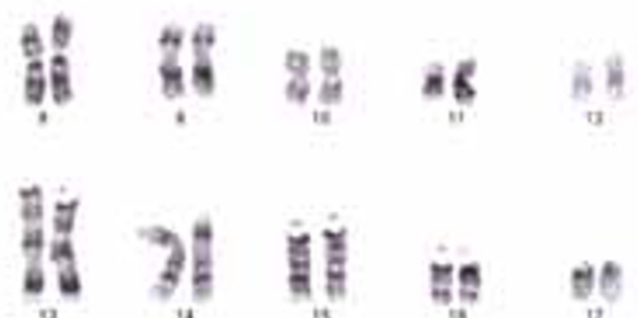

b)

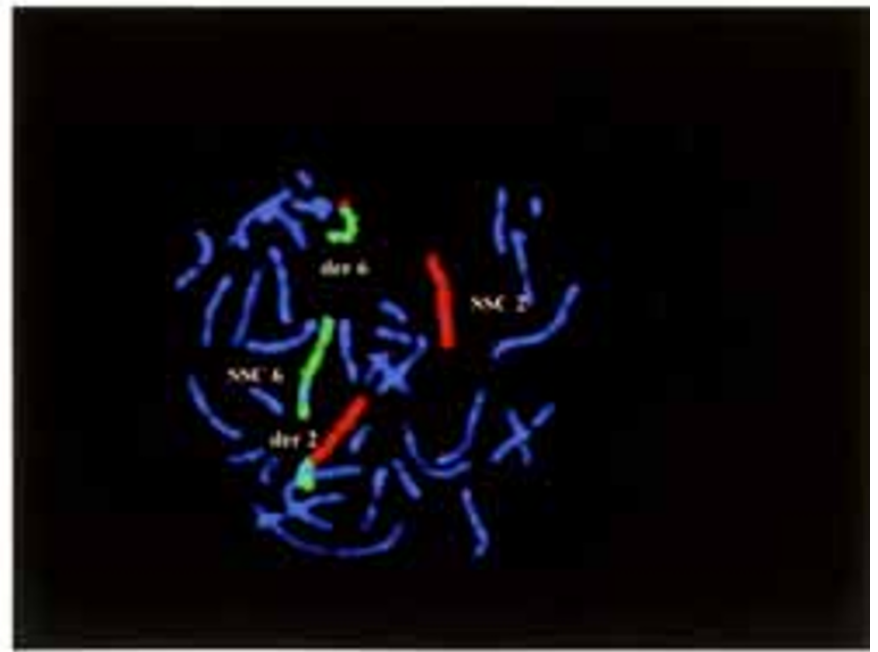

Figure 5. $\operatorname{rcp}(2 ; 6)(\mathrm{p} 17 ; \mathrm{q} 27)$

a) GTG-banding karyotype: the normal chromosomes are on the left, the rearranged chromosomes on the right; the locations of the breakpoints are indicated by arrows.

b) Dual-color chromosome painting: metaphase spread of a pig heterozygous carrier of the rearrangement. 
a)

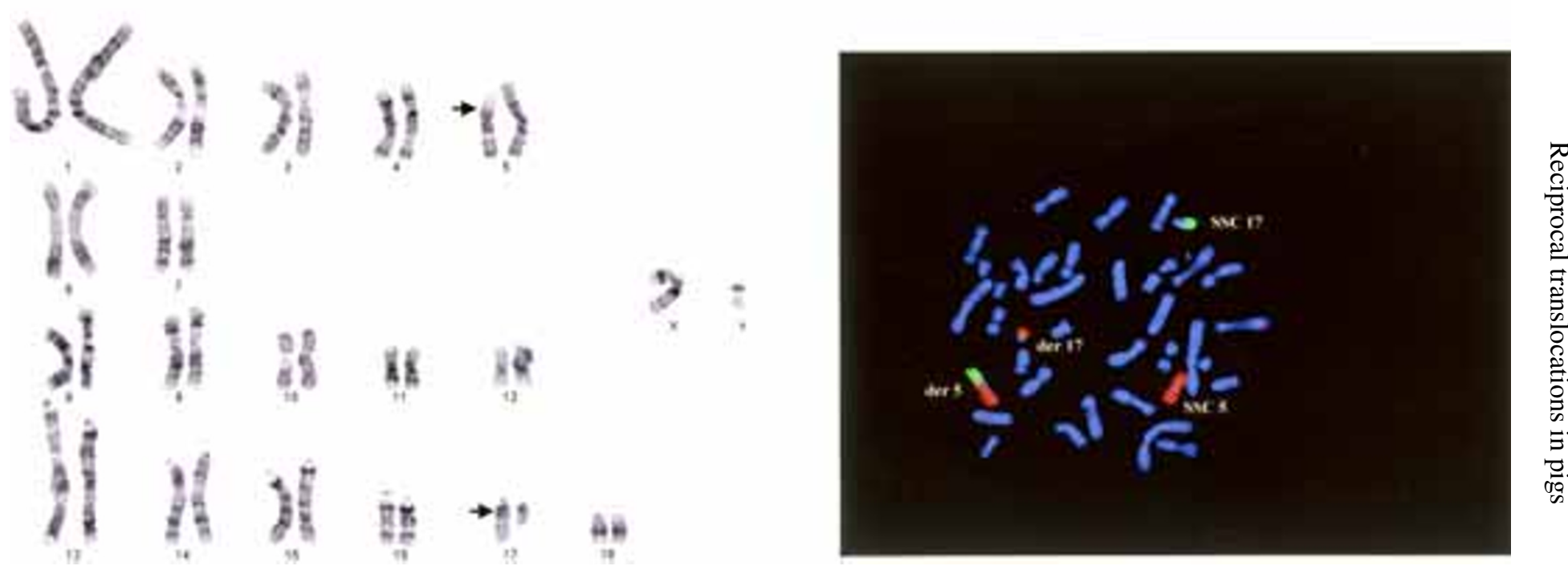

Figure 6. $\operatorname{rcp}(5 ; 17)(\mathrm{p} 12 ; \mathrm{q} 13)$

a) GTG-banding karyotype: the normal chromosomes are on the left, the rearranged chromosomes on the right; the locations of the breakpoints are indicated by arrows.

b) Dual-color chromosome painting: metaphase spread of a pig heterozygous carrier of the rearrangement. 
a)
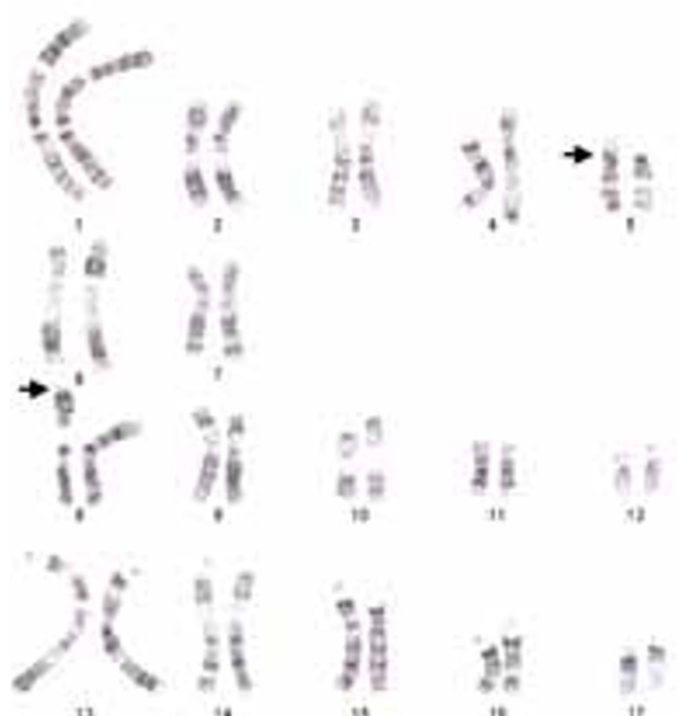

b)

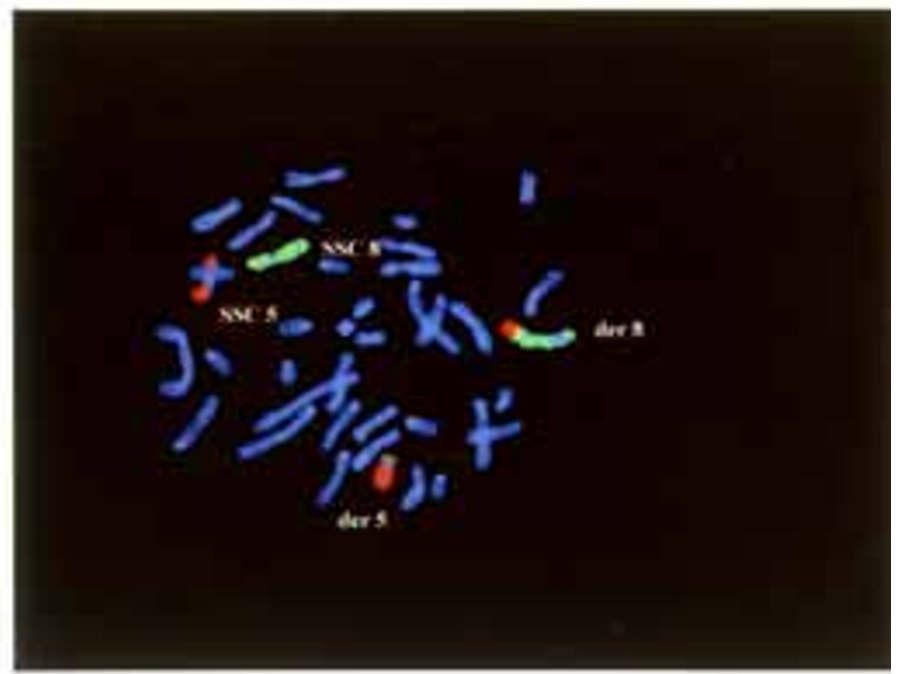

$?$
$?$
8
0
$?$
$?$

Figure 7. $\operatorname{rcp}(5 ; 8)(\mathrm{p} 11 ; \mathrm{p} 23)$

a) GTG-banding karyotype: the normal chromosomes are on the left, the rearranged chromosomes on the right; the locations of the breakpoints are indicated by arrows.

b) Dual-color chromosome painting: metaphase spread of a pig heterozygous carrier of the rearrangement. 
a)

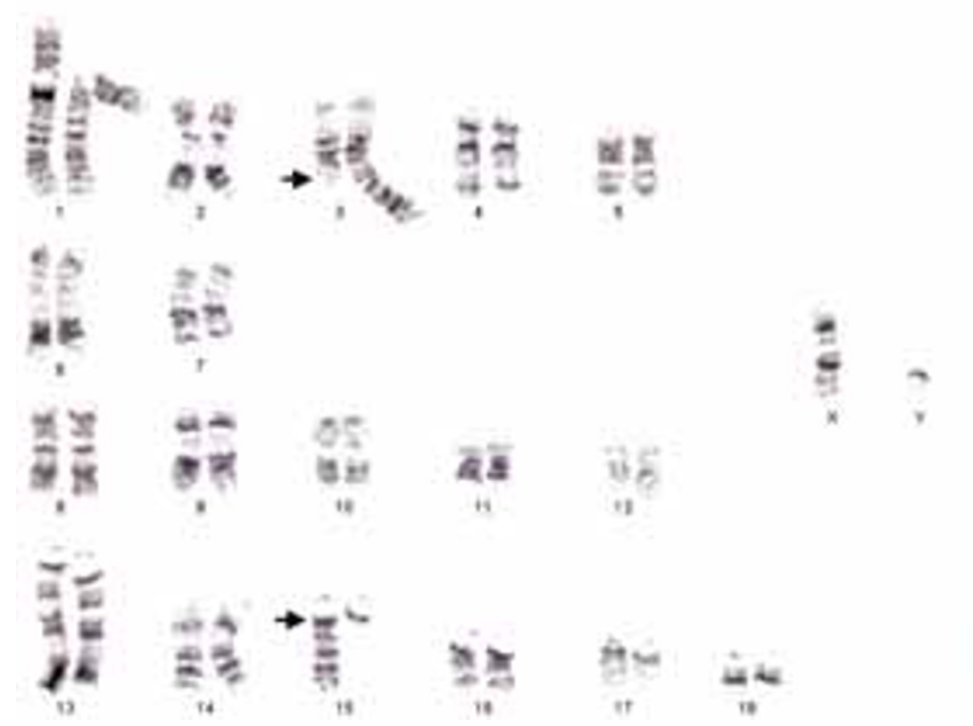

Figure 8. $\operatorname{rcp}(3 ; 15)(\mathrm{q} 27 ; \mathrm{q} 13)$

a) GTG-banding karyotype: the normal chromosomes are on the left, the rearranged chromosomes on the right; the locations of the breakpoints are indicated by arrows.

b) Dual-color chromosome painting: metaphase spread of a pig heterozygous carrier of the rearrangement. b)

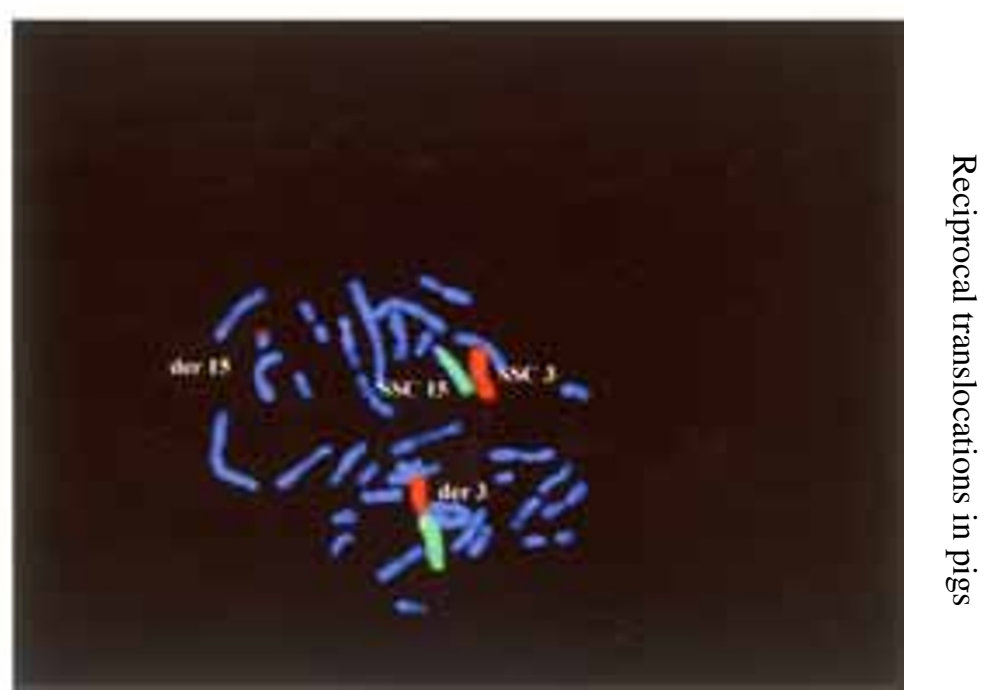

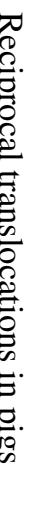


$(15 q 13 \rightarrow 15 q$ ter fragment, presenting a very characteristic banding pattern) appeared translocated to the q-terminal extremity of one chromosome 3. As for the previous case, the reciprocity of the exchange was very difficult to prove using the banding techniques, but, once again, the demonstration could be done using chromosome painting. In Figure $8 \mathrm{~b}$ we observed one normal chromosome 15 in green, as well as one normal chromosome 3 in red. The long dual-colored chromosome was the chromosome der(3). The small red-colored chromosome corresponded to chromosome der(15). As for case 6 , the residual pericentromeric chromosome 15 fragment (15cen $\rightarrow$ 15q13) on the der(15) chromosome appeared as not stained by the painting probe used. The chromosomal rearrangement could be described as $38, X Y, r c p(3 ; 15)(q 27 ; q 13)$.

\subsection{Zootechnical analyses}

Five out of eight reciprocal translocations described in this paper concerned young boars controlled before reproduction. Accordingly, the estimated incidence of reciprocal translocations in the sample studied (1 450 young boars belonging to French selected populations controlled independently over the $01 / 2000-06 / 2001$ period) was $0.34 \%$.

The remaining 3 translocations were identified in hypoprolific boars used in AI centers. We were provided with information concerning the reproductive performance of the sows sired by two of these boars only (cases 5 and 6). The boar carrier of the $2 / 6$ translocation sired 51 litters in two herds, with an average litter size of 8.30. The boar carrier of the $5 / 17$ translocation sired 25 litters again in two herds, with an average litter size of 7.4. The average reproductive performance of the sows sired by contemporary boars in the same herds was not known. Therefore, the exact effect of the translocations could not be estimated accurately. On the contrary, these results should be considered carefully due to the systematic practice of double AI within a $24 \mathrm{~h}$ period in the herds concerned. The young boar carrier of the 3/15 translocation was used to sire (experimentally) 6 litters in a commercial herd (14, 14, 6, 7, 9, 5 total piglets born, respectively). The average value (9.2) was $22 \%$ lower than the mean prolificacy of the herd over the same period (12 piglets born alive / litter).

Partial family analyses aimed at determining the origin of the translocations (acquired or de novo) were carried out for cases 2, 3, 4 and 7. The identification of one full-sister carrier of the $(5 ; 8)(\mathrm{p} 11 ; \mathrm{p} 23)$ translocation allowed us to prove the family transmission of the rearrangement. However, the parental origin (sire or dam carrier) has not yet been determined. In the other cases, the relatives controlled were all noncarriers. Further analyses should be carried out to confirm the de novo origin of the rearrangements. 


\section{DISCUSSION}

The total number of reciprocal translocations reported for the pig species in 1998 was 68 [4,8]. Since that time, 11 new reciprocal translocations have been published: $\operatorname{rcp}(8 ; 14)(\mathrm{p} 21 ; \mathrm{q} 25)$ and $\operatorname{rcp}(7 ; 13)(\mathrm{q} 13 ; \mathrm{q} 46)$ [7], $\operatorname{rcp}(2 ; 9 ; 14)(\mathrm{q} 23 ; \mathrm{q} 22 ; \mathrm{q} 25)$ and $\operatorname{rcp}(7 ; 15)(\mathrm{q} 24 ; \mathrm{q} 26)[20], \operatorname{rcp}(13 ; 17)(\mathrm{q} 41 ; \mathrm{q} 11)$ and $\operatorname{rcp}(2 ; 14)(q 13 ; q 27)$ [9], $\operatorname{rcp}(8 ; 10)(p 11 ; q 13)[22], \quad \operatorname{rcp}(1 ; 7)(q 17 ; q 26)$, $\operatorname{rcp}(4 ; 12)(\mathrm{p} 13 ; \mathrm{q} 13)$ and $\operatorname{rcp}(1 ; 6)(\mathrm{q} 17 ; \mathrm{q} 35)[25]$, and a $1 \mathrm{q}+/ 15 \mathrm{q}-$ translocation [18]. Including the eight new cases reported here, the total number of reciprocal translocations known in the pig species is presently 87 . More than one quarter (25/87) were described in our laboratory.

All the reciprocal translocations identified within the routine chromosomal control programmes are original ones (the chromosomes and/or the breakpoints differ systematically from one rearrangement to another). This result is in agreement with the observation made in man: only one out of several thousands described in the HCForum database [5] is recurrent (reciprocal translocation $(11 ; 22)(\mathrm{q} 23.3 ; \mathrm{q} 11.2)$ identified independently in more than 100 apparently unrelated families [15]).

The number of chromosomal rearrangements described annually in the pig species has strongly increased recently. About one third of the 87 reciprocal translocations published to date were identified from 1995 onwards. This can be explained by the intensification of the control programmes, especially in France [10], but also by the improvement of the laboratory techniques used [27]. $\mathrm{G}$ and/or $\mathrm{R}$ banding is presently used systematically and allows the detection of rearrangements modifying very slightly the size and/or the banding profiles of the chromosomes, as, for instance, in the case of the translocations $\operatorname{rcp}(15 ; 17)(\mathrm{q} 24 ; \mathrm{q} 21)$ and $\operatorname{rcp}(7 ; 8)(\mathrm{q} 24 ; \mathrm{p} 23)$ described in this paper. However, in certain cases, the resolution of classical banding techniques is not sufficient to characterize the rearrangements accurately. The location of the breakpoints, or the reciprocity of the chromosomal exchange are sometimes difficult to determine. It is very useful to supplement chromosome banding studies with molecular cytogenetic techniques in such cases. Dual-color chromosome painting experiments carried out for 7 out of 8 reciprocal translocations described in this paper allowed the improvement of the characterization of the rearrangement in 5 cases $(1,4,5,7$ and 8$)$, and the confirmation of the proposed hypotheses for the others. Additional FISH-based experiments could be carried out in the cases of rearrangements involving pericentromeric regions not stained by the painting probes used. Hybridization of BAC probes located in these pericentromeric regions could for example more accurately localize the breakpoints (see an example of such an application in [26]). The use of molecular cytogenetic techniques to characterize chromosomal rearrangements, classical in humans, is still little developed in animal species. To our knowledge, only 10 cases have 
been published so far: 4 in the pig species [17,21,24,25], 3 in cattle [11,16, 23], 2 in equines [2,3], and 1 in chicken [28].

Reciprocal translocations generally lead to an important decrease of the reproductive performance of carrier animals or of their mates (the estimated average effect on prolificacy was $-40 \%$ [8]). The information obtained for 3 out of the 8 translocations described here, although not very accurate, confirms this long known fact [13], and helps to justify the control programmes carried out. The young boars carrying chromosomal rearrangements were systematically slaughtered, although the exact effect of the abnormalities was not estimated. Such a decision avoids the diffusion of potentially unfavorable chromosomal rearrangements in the populations, but sometimes penalizes the selection schemes. To circumvent this problem, we are currently developing a new sperm-FISH method that will allow an accurate estimation of the rate of chromosomally unbalanced spermatozoa in boar semen. This criterion will help to predict in vitro the potential effect of any chromosomal rearrangement. Only abnormalities presenting high rates of unbalancedness might be proposed for eradication.

The estimated incidence of reciprocal translocations over the 2000/2001 period considered in this study is $0.34 \%$. The value obtained when considering a longer period is slightly lower. Out of 3200 independent analyses carried out since 1995 on young boars controlled before reproduction, 13 original chromosomal rearrangements were identified, including 8 reciprocal translocations [10]. This leads to an overall incidence of balanced structural chromosomal rearrangements in the French pig populations of $0.41 \%(0.25 \%$ for reciprocal translocations). Such epidemiological results, never reported for domestic animal species, are comparable to those estimated in man (2.5 liveborns out of 1000 carried balanced structural chromosomal rearrangements [1]).

\section{ACKNOWLEDGEMENTS}

We wish to express our gratitude to the staffs of the insemination centers, of the selection organizations as well as the herd-stock breeders, for the bloodtaking and all the arrangements concerning the animals.

\section{REFERENCES}

[1] Berger R., Cytogénétique humaine, in: Feingold J., Fellous M., Solignac M. (Eds.), Principes de génétique humaine, Hermann, Paris, 1998, pp. 33-58.

[2] Bowling A.T., Million L.V., Dileanis S., Physical mapping of genetic markers to chromosome 30 using a trisomic horse and evidence for maternal origin of the extra chromosome, Chromosome Res. 5 (1997) 429-431. 
[3] Breen M., Langford C.F., Carter N.P., Fischer P.E., Marti E., Gerstenberg C., Allen W.R., Lear T.L., Binns M.M., Detection of equine X chromosome abnormalities in equids using a horse $\mathrm{X}$ whole chromosome paint probe (WCPP), Vet. J. 153 (1997) 235-238.

[4] Chowdhary B.P., Cytogenetics and physical chromosome maps, in: Rothschild M.F., Ruvinsky A. (Eds.), The Genetics of the Pig, CABI, Oxon, 1998, pp. 199264.

[5] Cohen O., Mermet M.A., Demongeot J., HC Forum: a Web site based on an international human cytogenetic database, Nucleic Acid Research 29 (2001) 305-307.

[6] Committee for the Standardized Karyotype of the Domestic Pig, Standard karyotype of the domestic pig, Hereditas 109 (1988) 151-157.

[7] Danielak-Czech B., Switonski M., Slota E., First identification of reciprocal translocations in Polish pigs, J. Anim. Breed. Genet. 114 (1997) 69-78.

[8] Ducos A., Berland H.M., Pinton A., Séguéla A., Blanc M.F., Darré A., Sans P., Darré R., Les translocations réciproques chez le porc: état des lieux et perspectives, in: Journées Rech. Porcine France, 4-6 February 1997, Vol. 29, Institut technique du porc, Paris, pp. 375-382.

[9] Ducos A., Pinton A., Séguéla A., Berland H.M., Blanc M.F., Darré A., Darré R., Five new cases of reciprocal translocations in the domestic pig, Hereditas 128 (1998) 221-229.

[10] Ducos A., Pinton A., Berland H.M., Séguéla A., Brun-Baronnat C., Bonnet N., Darré R., Contrôle chromosomique des populations porcines en France: bilan de 5 années d'activité, in: Journées Rech. Porcine France, 5-7 February 2002, Vol. 34, Institut technique du porc, Paris, pp. 269-275.

[11] Gallagher D.S., Lewis B.C., De Donato M., Davis S.K., Taylor J.F., Edwards J.F., Autosomal trisomy $20(61, \mathrm{XX},+20)$ in a malformed bovine fetus, Vet. Pathol. 36 (1999) 448-451.

[12] Guéblez R., 15 ans d'IA en sélection, quels résultats?, Techniporc 24 (2001) 19-22.

[13] Gustavsson I., Chromosome aberrations and their influence on reproductive performance of domestic animals - a review, Z. Tierz. Züchtungsbiol. 97 (1980) 176-195.

[14] Henricson B., Bäckström L., Translocation heterozygosity in a boar, Hereditas 52 (1964) 166-170.

[15] Kaiser-Rogers K., Rao K., Structural chromosome rearrangements, in: Gersen S.L., Keagle M.B. (Eds.), The principles of clinical cytogenetics, Humana Press, Totowa, New Jersey, 1999, pp. 191-228.

[16] Kawakura K., Miyake Y., Murakami R.K., Kondoh S., Hirata T.I., Kaneda Y., Abnormal structure of the $\mathrm{Y}$ chromosome detected in bovine gonadal hypoplasia (XY female) by FISH, Cytogenet. Cell Genet. 76 (1997) 36-38.

[17] Konfortova G.D., Miller N.G.A., Tucker E.M., A new reciprocal translocation $(7 q+; 15 q-)$ in the domestic pig, Cytogenet. Cell Genet. 71 (1995) 285-288.

[18] Kosarcic S., Kosarcic D., Kovacevic M., The possible association of structural chromosome aberration with reproductive disturbances in the breeding pig, Acta Vet. (Beograd) 50 (2000) 155-162. 
[19] Legault C., Popescu C.P., Les translocations réciproques chez le porc domestique: détection, éradication et prévention, Élevage et Insémination 254 (1993) 1-12.

[20] Mäkinen A., Pitkänen T., Andersson M., Two cases of reciprocal translocations in domestic pigs producing small litters, J. Anim. Breed. Genet. 114 (1997) 377-384.

[21] Mäkinen A., Andersson M., Nikunen S., Detection of the X chromosomes in a Klinefelter boar using a whole human X chromosome painting probe, Anim. Reprod. Sci. 52 (1998) 317-323.

[22] Mäkinen A., Andersson M., Häkkinen A., Kuosmanen S., A reciprocal translocation between autosomes 8 and 10 in a boar used for artificial insemination service, Anim. Reprod. Sci. 56 (1999) 237-243.

[23] Miyake Y.I., Kawakura K., Murakami R.K., Kaneda Y., Minute fragment observed in a bovine pedigree with Robertsonian translocation, J. Hered. 85 (1994) 488-490.

[24] Pinton A., Ducos A., Séguéla A., Berland H.M., Darré R., Darré A., Pinton P., Schmitz A., Cribiu E.P., Yerle M., Characterization of reciprocal translocations in pigs using dual-color chromosome painting and PRINS, Chromosome Res. 6 (1998) 361-365.

[25] Pinton A., Ducos A., Berland H.M., Séguéla A., Brun-Baronnat C., Darré A., Darré R., Yerle M., Chromosomal abnormalities in hypoprolific boars, Hereditas 132 (2000) 55-62.

[26] Pinton A., Pailhoux E., Piumi F., Rogel-Gaillard C., Yerle M., Ducos A., Cotinot C., A case of intersexuality in pigs associated with a de novo paracentric inversion 9(p1.2;p2.2), Anim. Genet. 33 (2002) 69-71.

[27] Popescu C.P., Hayes H., Dutrillaux B., Techniques de cytogénétique animale, INRA Éditions, Paris, 1998.

[28] Ramos P.S., Bitgood J.J., Ponce De Leon A., Novel chromosomal translocation in chicken uncovered by double color FISH, Anim. Biotechnol. 10 (1999) 119-122.

[29] Schmitz A., Chardon P., Gainche I., Chaput B., Guilly M.N., Frelat G., Vaiman M., Pig standard bivariate flow karyotype and peak assignment for chromosomes X, Y, 3 and 7, Genomics 14 (1992) 352-357.

[30] Seabright M., A rapid banding technique for human chromosomes, Lancet 2 (1971) 971-972.

[31] Telenius H., Carter N., Bebb C.E., Nordenskjold M., Ponder-Bruce A.J., Tunnacliffe A., Degenerated oligonucleotide-primed PCR: general amplification of target DNA by a single degenerated primer, Genomics 13 (1992) 718-725.

[32] Tribout T., Ducos A., Maignel L., Bidanel J.P., Utilisation du système d'information BLUP pour la détection des verrats porteurs d'anomalies chromosomiques, Techniporc 23 (2000) 19-24.

[33] Yerle M., Schmitz A., Milan D., Chaput B., Monteagudo L., Vaiman M., Frelat G., Gellin J., Accurate characterization of porcine bivariate flow karyotype by PCR and fluorescence in situ hybridisation, Genomics 16(1993) 97-103. 